Int. J. Electrochem. Sci., 12 (2017) $7216-7226$

\title{
Glucose Oxidase Embedded ZnO Nanowires/Ferrocenyl- Alkanethiol Array for efficient glucose-sensing application
}

\author{
Bairui Tao ${ }^{1,2 *}$, Rui Miao ${ }^{1}$,Wenyi $\mathrm{Wu}^{1}$, Fengjuan Miao ${ }^{1 *}$ \\ ${ }^{1}$ College of Communications and Electronics Engineering, Qiqihar University, Heilongjiang 161006, \\ China \\ ${ }^{2}$ Modern Education Technology Center, Qiqihar University, Heilongjiang 161006, China \\ *E-mail: tbr_sir@163.com; miaofengjuan@163.com
}

doi: $10.20964 / 2017.08 .39$

Received: 28 July 2016 / Accepted: 1 June 2017 / Published: 12 July 2017

\begin{abstract}
One-dimensional $\mathrm{ZnO}$ nanowires/ferrocenyl-alkanethiol array is synthesized on silicon substrate combined by self-assembled and low temperature aqueous methods. Electro-catalytic responses of glucose oxidase/ $\mathrm{ZnO}$ nanowires/ferrocenyl-alkanethiol array/Silicon (GOx/ZnO NWs/FcC11SH/Si) electrode are detected deeply. The $\mathrm{ZnO}$ nanowires/ferrocenyl-alkanethiol array has provided a favorable environment to the immobilization of glucose oxidase. The morphology and crystal structure of the as-grown products have been characterized by many methods, including scanning electron microscopy (SEM), X-ray diffraction (XRD) and electrochemical test. Electrochemical results demonstrated that the well configuration $\mathrm{GO}_{\mathrm{x}} / \mathrm{ZnO} \mathrm{NWs} / \mathrm{FcC} 11 \mathrm{SH} / \mathrm{Si}$ possessed excellent electrocatalytic activity to glucose, which provide a meaningful way for the practical applications in clinical, environmental, and food analysis.
\end{abstract}

Keywords: Electrochemical behavior; Glucose oxidase; ZnO NWs/FcC11SH/Si; Biosensor

\section{FULL TEXT}

(C) 2017 The Authors. Published by ESG (www.electrochemsci.org). This article is an open access article distributed under the terms and conditions of the Creative Commons Attribution license (http://creativecommons.org/licenses/by/4.0/). 